\title{
Ovarian follicle cell enhancers from the Drosophila yolk protein genes: different segments of one enhancer have different cell-type specificities that interact to give normal expression
}

\author{
Susan K. Logan ${ }^{1,3}$ and Pieter C. Wensink ${ }^{2,4}$ \\ The Rosenstiel Center and the ${ }^{1}$ Departments of Biology and ${ }^{2}$ Biochemistry, Brandeis University, Waltham, Massachusetts \\ 02254-9110 USA
}

This paper examines ovarian transcription of the divergently oriented yolk protein genes 1 and 2 (yp1 and yp2) of Drosophila melanogaster. We report germ line transformation results demonstrating that $y p 1$ and $y p 2$ are transcribed in the same subpopulations of ovarian follicle cells. Our results show that this expression pattern is directed by two enhancers: ovarian enhancer 1, located between the genes, and ovarian enhancer 2, located within the first exon of $y p 2$. Analysis of the expression pattern resulting from alterations in ovarian enhancer 1 demonstrates that different segments of this enhancer have different positive or negative effects on the cell-type specificity of transcription.

[Key Words: Drosophila; yolk protein genes; ovarian enhancers]

Received September 19, 1989; revised version accepted January 12, 1990.

Yolk protein genes 1 and 2 (yp1 and yp2) of Drosophila melanogaster encode two of the three abundant food proteins found in eggs (Barnett et al. 1980). These neighboring and divergently transcribed genes are expressed in a highly specific pattern during development. Their transcripts have been detected only in adult females and only in two tissues: ovarian follicle cells and fat body cells (Barnett and Wensink 1981; Brennan et al. 1982; Garabedian et al. 1985, 1986). Previous results have demonstrated that this expression pattern is directed by two enhancer regions located between the genes (Fig. 3a; Garabedian et al. 1985, 1986; Shepherd et al. 1985; Logan et al. 1989|. Each of these enhancer regions directs a different tissue specificity: One directs expression in female fat body cells, and the other, ovarian enhancer 1 (oe1), directs expression in ovarian follicle cells. An additional region regulating yolk protein gene transcription in follicle cells has been found immediately downstream of the cap site and within the first exon of yp2 (Logan et al. 1989).

This paper examines the follicle cell-type specificity of yolk protein gene expression and the transcriptional regulatory elements directing this specificity. We used P-element-mediated transformation of a gene fusion structure to demonstrate that the intergenic region di-

${ }^{3}$ Current address: Department of Anatomy and Oral Biology, University of California, San Francisco, California 94143 USA.

${ }^{4}$ Corresponding author. rects the same follicle cell-type-specific expression from each of the yolk protein promoters. This specificity is the same as that directed by the oel enhancer alone and similar to that directed by a second ovarian enhancer, oe2, located in the first exon of yp2. The results also show that oel is composed of segments that have different positive or negative effects on the cell-type specificity of transcription.

As background for our description of expression patterns, we review here the differentiation of ovarian follicle cells (Margaritis et al. 1980). As shown in Figure 1A, all follicle cell subtypes are thought to be derived from $\sim 1000$ follicular epithelial cells. This precursor population ceases mitotic division by stage 6 of eggchamber development and then differentiates into three follicle cell subtypes: border cells, cells covering the nurse cells, and columnar cells. The 6-10 border cells migrate between the nurse cells, starting from the anterior pole of the egg chamber and eventually arriving at the anterior surface of the oocyte (Fig. 1B). Border cells secrete the micropylar apparatus through which fertilization occurs (King 1970). The function of the 50-100 cells that stretch into a thin squamous layer covering the nurse cells is unknown. The third cell type derived from the precursor pool is the columnar cell type. By stage 11, these cells undergo differentiation into three additional cell types: anterior pole cells, posterior pole cells, and columnar main body cells. Anterior pole cells intercalate between nurse cells and the oocyte where 

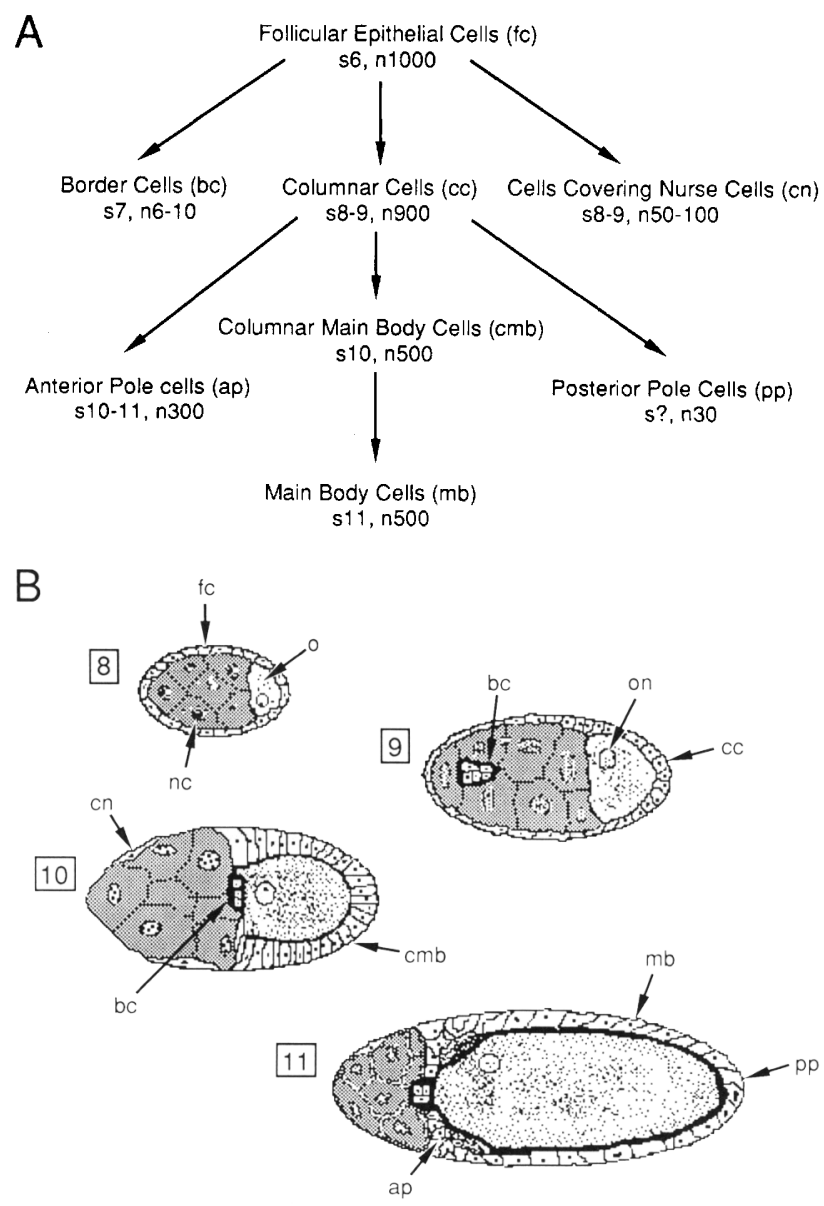

Figure 1. (A) Differentiation lineage of Drosophila ovarian follicle cells (modified from Margaritis et al. 1980). Lineage is indicated by arrows. Cell type abbreviations are shown in parentheses. The approximate developmental stage of appearance (s) and the approximate number of cells (n) are listed under each cell type name. Unknown information is indicated by a question mark. $(B)$ Drawings of sectioned egg chambers /modified from King 1970). The boxed numbers indicate developmental stages. (o) Oocyte; (nc) nurse cell; (on) oocyte nucleus.

they appear to form the respiratory appendages and operculum of the mature oocyte. The posterior pole cells appear to form the aeropyle, a structure thought to be involved in embryonic respiration. Finally, the main body cells secrete eggshell over most of the oocyte.

\section{Results}

The 3' half of oe1 is necessary for ovarian expression

Germ line transformation experiments have identified an ovarian enhancer region, oel, located between yp1 and $y p 2$ at position -343 to -43 (unless otherwise noted, all nucleotide positions are relative to the yp 2 cap site, +1 ; Logan et al. 1989). These experiments also demonstrated that the $5^{\prime}$ half of oel is necessary for high levels of ovarian transcription from both of the divergently transcribed $y p 1$ and yp2 promoters (Fig. 2A,B, structure b; Logan et al. 1989).
To determine whether the $3^{\prime}$ half of oel is also necessary for ovarian expression, this half was deleted from the yp $1+2$ gene pair and the resulting structure introduced into the Drosophila germ line by P-element-mediated transformation (Fig. 2A, structure c). In this structure, the $y p 1$ and $y p 2$ genes are marked by M13 bacteriophage DNA insertions that allow transcripts of the introduced genes to be distinguished from those of the endogenous yolk protein genes. Two independently transformed lines were examined and gave the same result. The $3^{\prime}$ deletion reduces yp 1 transcript levels in ovaries at least 10 -fold relative to transformants with the intact gene construct (Fig. 2B, lane 1 vs. lanes 3 and 4). The yp2 gene is not transcribed in the 3 ' deletion because most of the yp2 promoter is missing. Because the fat body level of yp1 expression from this deletion is the same as that from the complete yp $1+2$ construct, we conclude that the yp1 promoter is not damaged in the $3^{\prime}$ deletion construct (Fig. 2B, lane 5 vs. lanes 6 and 7). Thus, the reduced yp1 RNA level in ovaries indicates that the $3^{\prime}$ half of oel is necessary for full levels of ovarian expression.

Because deletion of each half of oel reduces expression in ovaries, it is likely that oel is composed either of more than one component or of one component that bridges the junction between the halves $\mid-159$ to -164 ; Fig. 2). Results described below indicate that the former alternative is correct by demonstrating that oel regions located upstream and downstream of the junction direct expression in different subpopulations of follicle cells. Furthermore, the fact that deletion of either half of oel results in at least a 10-fold decrease in message levels suggests that the two halves act cooperatively to produce normal levels of ovarian transcripts.

\section{Cell-type specificity of ovarian transcription from the yp1 and yp2 promoters}

Before investigating the possibility that different segments of oel direct expression in different follicle cells, we first needed to establish the follicular expression pattern of each of the two normal yolk protein gene promoters influenced by the entire intergenic region. Previous studies established the follicular cell-type specificities of the oel enhancer through analysis of its influence on a heterologous Drosophila promoter fused to the $\beta$-galactosidase gene (e.g., structure d in Fig. 3; Logan et al. 1989). To examine follicular expression from the normal yolk protein promoters, rather than from a heterologous promoter, we transformed and analyzed the expression pattern of the fusion structure diagrammed in Figure 3b. This structure, pCR2, includes the two yolk protein promoters, some of the transcribed yolk protein DNA, and all of the DNA normally occurring between the yolk protein promoters. Previous studies indicated that the yolk protein DNA segment included in pCR2 contains all of the cis-acting DNA necessary to produce yp 1 and $y p 2$ transcripts at the same ovarian and fat body levels as produced by the entire $y p 1+2$ gene pair (Fig. 2, structure a; Garabedian et al. 
A

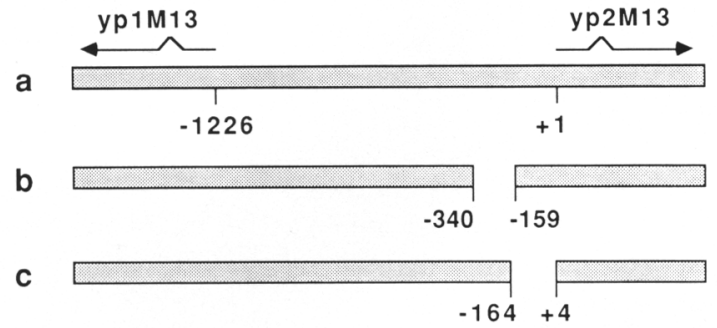

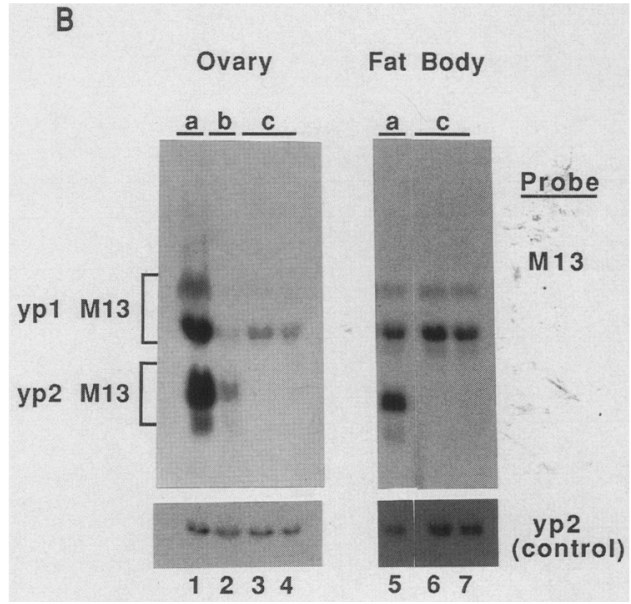

Figure 2. Transcription patterns from deletion constructions. $(A)$ The normal arrangement of yp1 and yp2 genes (structure $a)$ which, in these constructions, have M13 insertions in the second exon-coding regions. The arrows indicate the transcription unit, with introns marked by carets and $3^{\prime}$ ends by arrowheads. The deletion end points are given relative to the yp2 cap site (structures $b$ and $c$ ). (B) An autoradiograph of Northern blots of total RNA from flies transformed with the structures shown in $A$. $(a-c)$ The introduced yolk protein constructs. RNA is from dissected fat bodies $(2 \mu \mathrm{g}$ RNA/lane) or ovaries (10 $\mu \mathrm{g}$ RNA/lane). The M13 probe detects multiple transcripts from the yp1M13 and yp2M13 genes, resulting from transcription terminations within the M13 fragment (Garabedian et al. 1985). Below is an autoradiograph of the same blot rehybridized to a yp2 probe after removal of the M13 label. This control indicates that there are similar amounts of RNA in each lane.

1985, 1986). In pCR2, the DNA downstream of yp1 nucleotide +37 was replaced by the Drosophila alcohol dehydrogenase gene $(A d h)$ and the DNA downstream of yp2 nucleotide +105 was replaced by the Escherichia coli $\beta$-galactosidase gene (lacZ). This structure allows activity of each promoter to be tested separately by histological assays for the different enzyme activities.

When pCR 2 is introduced into the germ line, both yolk protein promoters have the expected general developmental specificities. In all five independently transformed lines, each promoter is expressed only in ovaries and fat body cells (Figs. 4a and 5a). Each is also expressed only in females. The $\beta$-galactosidase staining assays shown in Figure 4a show the female specificity of yp2 promoter expression. The spectrophotometric assays of whole fly extracts shown in Table 1 are a better assay of sex-specific expression from yp1, because histological staining methods used to determine alcohol dehydrogenase enzyme $(\mathrm{ADH}$, the gene product of $A d h)$ activity often dislodge fat body cells from flies (Fig. 5a, abdomen).

Closer observation of the $\beta$-galactosidase staining pattern reveals the cell-type specificity of ovarian expression from the $y p 2$ promoter in $\mathrm{pCR} 2$. This expression is the result of transcription from the $y p 2$ promoter because no $\beta$-galactosidase activity is observed in ovaries of untransformed flies (Garabedian et al. 1986). In pCR2 transformants, expression is limited to follicle cells but does not occur in all follicle cell types. The nurse cell region (Fig. 4b, thick arrow), which contains a follicle cell type covering the nurse cells and a follicle cell type in between nurse cells (Fig. 1, cn and bc), does not stain. In contrast, strong staining occurs in columnar follicle cells and some of the follicle cell types derived from them at later stages (Fig. $4 \mathrm{~b}, \mathrm{c}$ ). Columnar cell staining is first detected at stage 8 of egg-chamber development, becomes strong by stage 9 , and continues through stage 10 , when these cells begin differentiating into anterior pole cells and columnar main body cells. Both anterior pole cells and columnar main body cells stain in stage 10 egg chambers. During a staining reaction, anterior pole cells are the first to stain, perhaps because of higher permeability to the staining compound or higher levels of $\beta$-galactosidase activity. This staining demonstrates that anterior pole cells do have yp2 promoter activity that might otherwise have been obscured by the neighboring columnar main body cells, which are more numerous and cover a much larger area of the oocyte surface. Finally, posterior pole cells differentiate from columnar cells later in egg chamber development and stain in stage 12 and 13 egg chambers (data not shown). This late-stage staining of posterior pole cells is highly variable, ranging from no staining to very dark staining, perhaps reflecting normal biological variation in egg chamber development or a brief and, therefore, rarely observed period of expression.

Staining in the main body region ceases at different stages in different transformed lines. In one line, staining is not detected after stage 10, when columnar main body cells differentiate into main body cells by flattening to cover the enlarging central region of the oocyte (Figs. 1 and 4 b). In three other lines, main body cell staining is more variable in persistence and gradually decreases during stages 12 and 13 (Fig. 4c).

In summary, the yp 2 promoter transcription is limited to columnar follicle cells and three cell populations derived from them: the anterior pole cells, columnar main body cells, and posterior pole cells. The pattern of $\beta$-galactosidase activity after stage 10 is complex: Activity always occurs in anterior pole cells, occasionally in pos- 
a

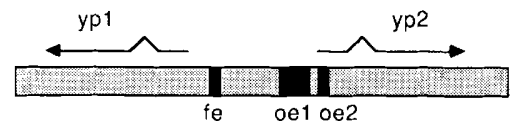

b

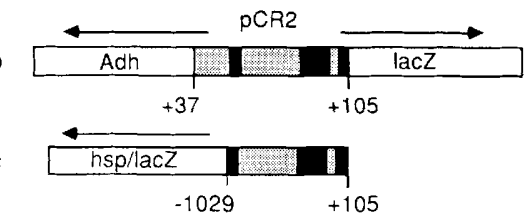

$d$

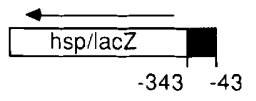

e

$f$

g

h
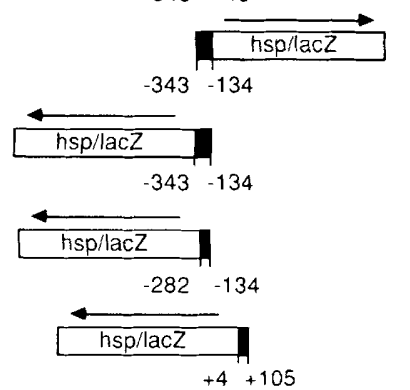

Figure 3. Germ line transformation with reporter structures. Transformed structures are shown at left $(a-h)$, with reporter DNA represented by open boxes and yolk protein DNA represented by shaded and solid boxes. The solid boxes represent enhancers identified in previous studies [(fe) fat body enhancer; (oe1) ovarian enhancer 1] and in this study [(oe2) ovarian enhancer 2]. All yolk protein nucleotide positions are aligned with corresponding positions in the endogenous gene structure $(a)$ and are relative to the yp2 cap site (except +37 , which is relative to the $y p 1$ cap site). Orientation of reporter gene transcription is shown by straight arrows. Other symbols are as in Fig. 2 . Germ line inserts of structures $c-h$ have the yolk protein DNA flanked by $\sim 7.3 \mathrm{~kb}$ of $h s p-l a c Z$ DNA on one side and $\sim 7.2 \mathrm{~kb}$ of $r y$ gene DNA on the other side. A summary of the expression patterns in columnar main body cells $(\mathrm{cmb})$, border cells $(\mathrm{bc})$, and anterior pole cells (ap) is shown at right. Staining intensity: $|-|$ undetectable $|+|$ very faint $;|++|$ very strong; $(\#)$ one line stains very faintly and three do not stain, $\left(^{*}\right)$ all three lines have different follicle cell-staining patterns.

terior pole cells, and with line-to-line variation in main body cells. The latter variation suggests that main body cell expression is more sensitive to chromosomal position effects.

The ovarian pattern of $\mathrm{ADH}$ activity resulting from $y p 1$ promoter transcription is nearly identical to that of $\beta$-galactosidase from the $y p 2$ promoter. Staining occurs predominantly over the columnar cells where it is weak at stage 8 and strong in stages 9 and 10. Dark staining of the anterior pole cells at stage 10 and their persistent staining after stage 11 indicate that these cells also transcribe from the $y p 1$ promoter (Fig. $5 \mathrm{~b}$, arrows). The ADH activity observed is the result of yp1 promoter transcription because the $A d h$ null mutant flies into which pCR2 was introduced do not stain under these assay conditions (Fig. 5c). Furthermore, endogenous ADH activity in ovaries of wild-type flies has an entirely different celltype specificity, principally before stage 8 and in the nurse cell region (Fig. 5d). However, stain produced by
$\mathrm{ADH}$ activity appears to diffuse and nonspecifically stain all tissues upon prolonged staining treatment. For this reason, low levels of specific expression from the yp1 promoter, for example, in the posterior pole cells, may not have been detected.

We conclude that the DNA between +37 of yp1 and +105 of yp2 directs ovarian expression from both yolk protein promoters in a pattern very similar to that observed for the endogenous genes by previous in situ hybridization experiments (Brennan et al. 1982). However, the earlier experiments do not appear to have had the resolution necessary to detect yolk protein gene transcripts in small populations of follicle cells such as the border cell and anterior pole cell populations detected by the staining reported here. For the purposes of this paper, the expression pattern of pCR2 will serve as the wildtype pattern for yolk protein genes.

\section{Different segments of oe1 direct different cell-type specificities}

Because the results reported in the first section indicate that oel may be composed of several components, we investigated the possibility that different oel fragments direct different cell-type expression patterns. To accomplish this, oel fragments were placed upstream of a reporter structure composed of the Drosophila hsp 70 gene promoter region fused to the $\beta$-galactosidase structural gene. First, we determined that this reporter structure responds to the large intergenic region in the same manner as the yolk protein promoters do. The yolk protein DNA included in $\mathrm{PCR} 2$ was placed upstream of the hsp promoter-lac $Z$ gene (Fig. 3, structure c). The fusion site in yolk protein DNA $(-1029$ relative to yp2 and -196 relative to yp1) placed the $h s p 70$ cap site within one nucleotide of the normal position of the $y p 1$ cap site. In the four independently transformed lines, expression from this structure is limited to female fat bodies and ovaries. With one exception, the ovarian cell-type specificity is the same as that observed for the two yolk protein promoters in pCR2 (Fig. 6a). The exception is very faint staining of border cells in all transformed lines. Border cell staining does not occur in either of the lines transformed with the same hsp-lacZ structure lacking yolk protein DNA but containing a functional $h s p$ promoter (data not shown). Thus, border cell expression appears to be due either to a specific interaction between the $h s p$ promoter region and yolk protein DNA or to deletion of a border cell negative regulatory element in the yolk protein DNA between -195 and +37 relative to yp1. Results reported below suggest that the latter possibility is correct by demonstrating that border cell expression can be independently regulated. We conclude that the $y p 1+2$ intergenic region and the first $105 \mathrm{bp}$ of yp2 direct nearly identical cell-type specificities from the $h s p$ promoter and the two yolk protein promoters in pCR2.

Because the $h s p 70$ promoter responds to the large intergenic region in nearly the same manner as yolk protein promoters, we used this heterologous promoter to 

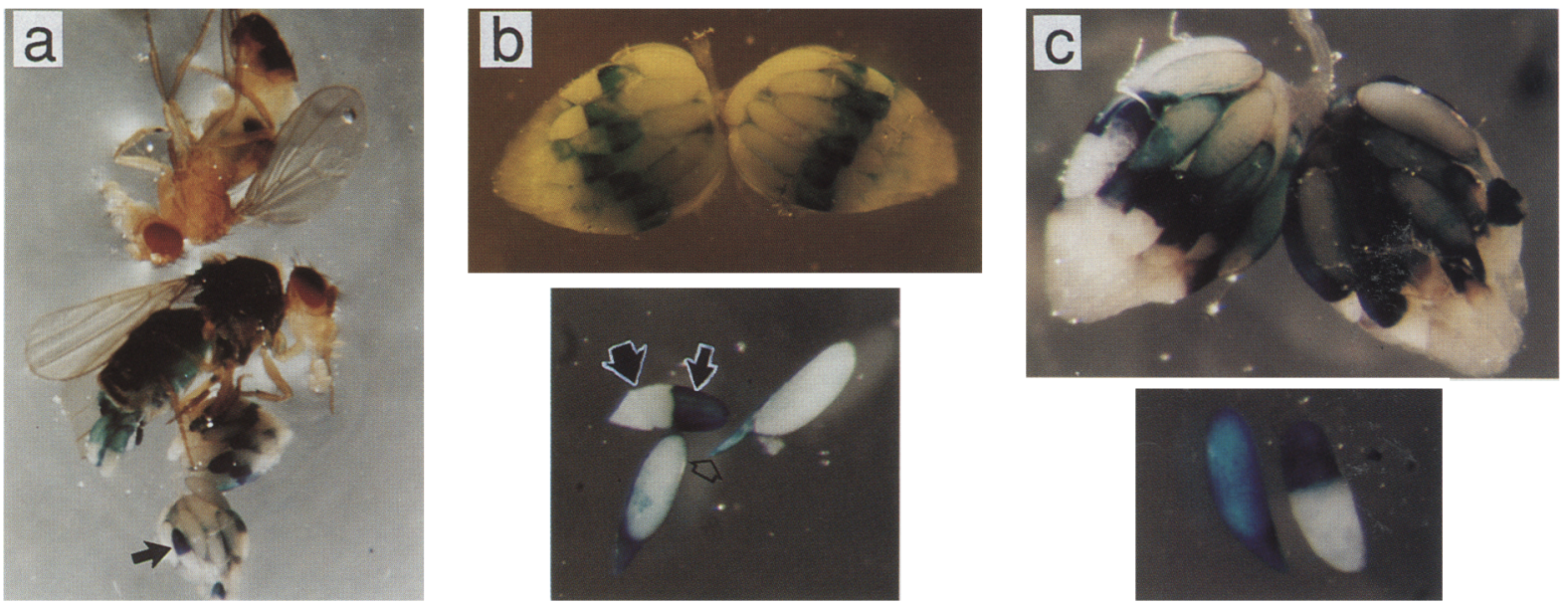

Figure 4. $\beta$-Galactosidase activity from pCR2. (a) X-gal-stained male (top) and female (bottom) including dissected ovaries (arrow). Fat body cells are located under the abdominal and thoracic cuticle. Fat body cells also occur in the head and stain if the head is opened, allowing penetration of the staining compound (not shown). (b and $c)$ X-gal-stained ovaries (top) and egg chambers $(b o t t o m)$ from different transformed lines. Egg chambers are arranged in the ovary in the order of their development. Early stages are at the anterior and late stages at the posterior, where the two ovaries touch in $b$ and $c$ (both at top). The oocyte (thin arrow) and nurse cell (thick arrow) portions of a stage $10 \mathrm{egg}$ chamber are shown in $b$. The anterior region (open arrow) of a stage-13 egg chamber is also shown.

test activity of oel components. Previous work examined the ovarian expression pattern produced when the entire oel is placed upstream of this $h s p 70$ promoter (Logan et al. 1989). The pattern was essentially identical to that for pCR2 and for the $h s p 70$ promoter influenced by the intergenic region (Fig. $3 \mathrm{~d}$ and $6 \mathrm{~b}$ ).

Removing 91 bp from the $3^{\prime}$ end of oel causes major changes in ovarian expression. However, expression is still limited to female ovarian follicle cells. The changes are similar when the resulting fragment is placed in either orientation (three independent lines in one orientation, four in the other; Fig. 3e,f). One major difference from the pattern produced by the entire enhancer is that six of the seven lines do not stain in columnar main body cells, the major class of cells expressing under the influence of the entire enhancer (Fig. 6c). In the seventh line, only very weak staining occurs in these cells (Fig. 6d). Anterior pole cell expression directed by this fragment appears normal in six of the seven lines and is weak in the seventh line. At stage 10, anterior pole cells are located between nurse cells and the oocyte and can be seen as a ring at the circumference of egg chambers (Fig. 6c, thick arrow).

A second major difference in expression occurs in border cells. In every transformed line, the border cells stain much more strongly than in lines that have the entire oel region. This border cell expression is unlikely to be due to chromosomal position effects because it is observed in every transformed line. The cluster of border cells can be seen as a small darkly stained dot in each egg chamber (Fig. 6c, thin arrows). At higher magnification, the border cell cluster appears as a dot that is anterior to, or inside, the ring of anterior pole cells, depending on the developmental stage of the chamber. Border cell expression is most clearly seen in egg chambers from the line that expresses weakly in anterior pole cells (Figs. 6e and 7). Additionally, the migration pattern of border cells from the anterior pole of the
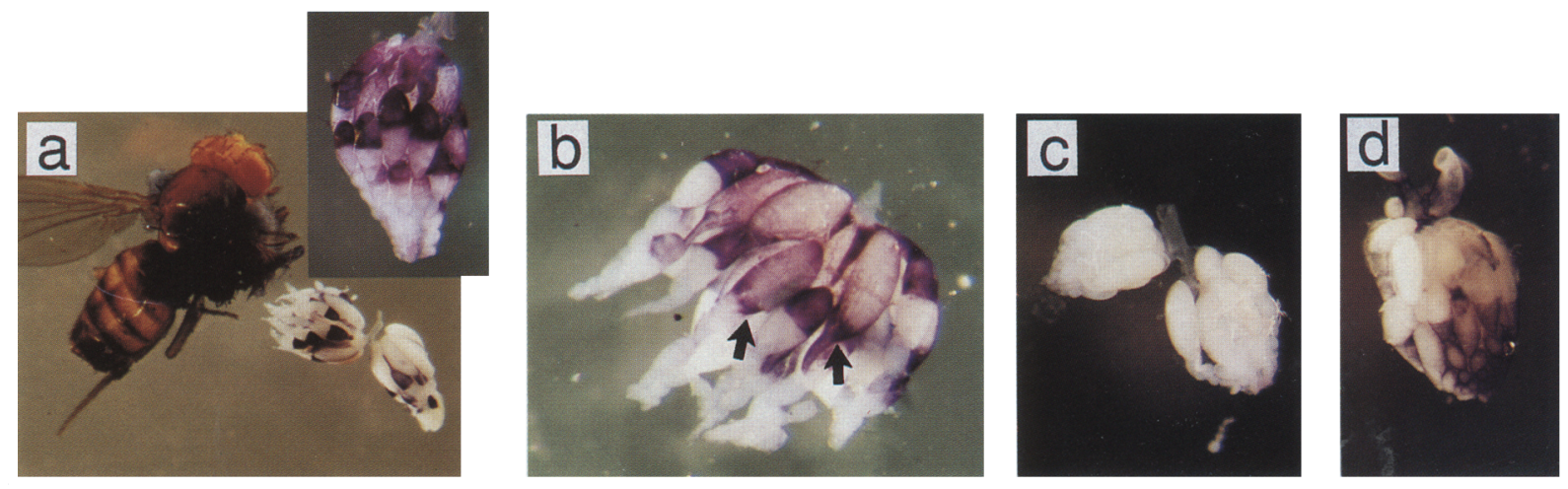

Figure 5. $\mathrm{ADH}$ staining activity from pCR2. (a) Female $A d h^{f n 6}, \mathrm{pCR} 2$-transformed fly with dissected ovaries (lower right and inset). (b) Ovary from an $A d h$ null fly $\left(A d h^{f n} 6\right)$ transformed with pCR2 showing anterior staining (arrows). (c) Ovary from an untransformed $A d h^{\text {fno }}$ (FCB) strain. (d) Ovary from an untransformed $r y^{-} A d h^{+}$fly. Arrows indicate the anterior pole cell region. 
Table 1. ADH activity in wild-type, mutant, and transformed flies

\begin{tabular}{|c|c|c|}
\hline \multirow[b]{2}{*}{ Fly strain } & \multicolumn{2}{|c|}{ ADH activity } \\
\hline & units/1 female & units $/ 5$ males \\
\hline$A d h^{f n 6} c n ; r y^{506}$ & & \\
\hline $\begin{array}{l}(\text { Adh mutant) } \\
A d h^{+} c n ; r y^{506}\end{array}$ & $0.003 \pm 0.006$ & $0.007 \pm 0.04$ \\
\hline $\begin{array}{l}\text { (Adh wild type) } \\
A d h^{f n 6} 6 n \cdot \\
506 .\end{array}$ & $0.50 \pm 0.03$ & $0.91 \pm 0.3$ \\
\hline $\begin{array}{l}r y^{+} \text {yp1/Adh } \\
\text { (Adh mutant transformed } \\
\text { by pCR2) }\end{array}$ & $0.70 \pm 0.09$ & $-0.03 \pm 0.02$ \\
\hline
\end{tabular}

Averages of triplicate enzymatic assays are reported with the $95 \%$ confidence interval $( \pm)$, where 1 unit $=1 \times 10^{-3} A_{340} / 2$ $\min$.

egg chamber (Fig. 7a) between the nurse cells (Fig. 7b) to reach a position at the anterior surface of the oocyte (Fig. 7c) can be visualized in egg chambers from this line.

Removing 61 bp from the $5^{\prime}$ end of the truncated oel region causes little change in its cell-type specificity (Fig. 3, structure g vs. f). All eight lines independently transformed by structure $g$ have ovarian and egg chamber staining patterns similar to those shown in Figure 6c. Expression is strong in anterior pole cells and border cells but does not occur in columnar main body cells.

We conclude that different segments of oel have different cell-type specificities. The central 149 bp is an enhancer that directs transcription in anterior pole cells and in border cells. The 3 '-terminal 91 bp has two effects on cell-type specificity when added to the central region: It greatly decreases border cell expression and causes expression in columnar main body cells. Finally, the $5^{\prime}$-ter- minal 61 bp has no detectable effect on cell-type specificity.

\section{A second ovarian enhancer is located in the first exon of yp2}

A region from the first exon of yp2 influences the level of yp1 expression in ovaries (Logan et al. 1989). We tested the enhancer properties of this region by placing it upstream of the $h s p-l a c Z$ reporter structure in the orientation shown in Figure 3 (structure h). In this orientation, $\beta$-galactosidase expression cannot be due to transcription from the truncated yp2 promoter present in this region. Two of the three independently transformed lines express strongly in columnar follicle cells, very weakly in border cells, and not at all in any other adult cell type. The third transformed line does not express in any adult tissue, presumably due to a negative effect from chromatin at the site of insertion. Although follicle cell specificity was directed by this enhancer, stage specificity was not. One of the lines stained in stages 12 and 13 and the other in stages 9-13 (Fig. 6f). These results demonstrate that this 102-bp region is a follicle-cell-specific enhancer, and led us to name it ovarian enhancer 2 (oe2).

\section{Ovarian transcript levels correlate with the histochemical staining results}

We have described indirect, histological assays of the ability of yolk protein DNA to direct ovarian transcription from the heterologous $h s p 70$ promoter. To correlate these assays with a more direct measure of $h s p$ promoter activity, we assayed the ovarian level of transcripts from
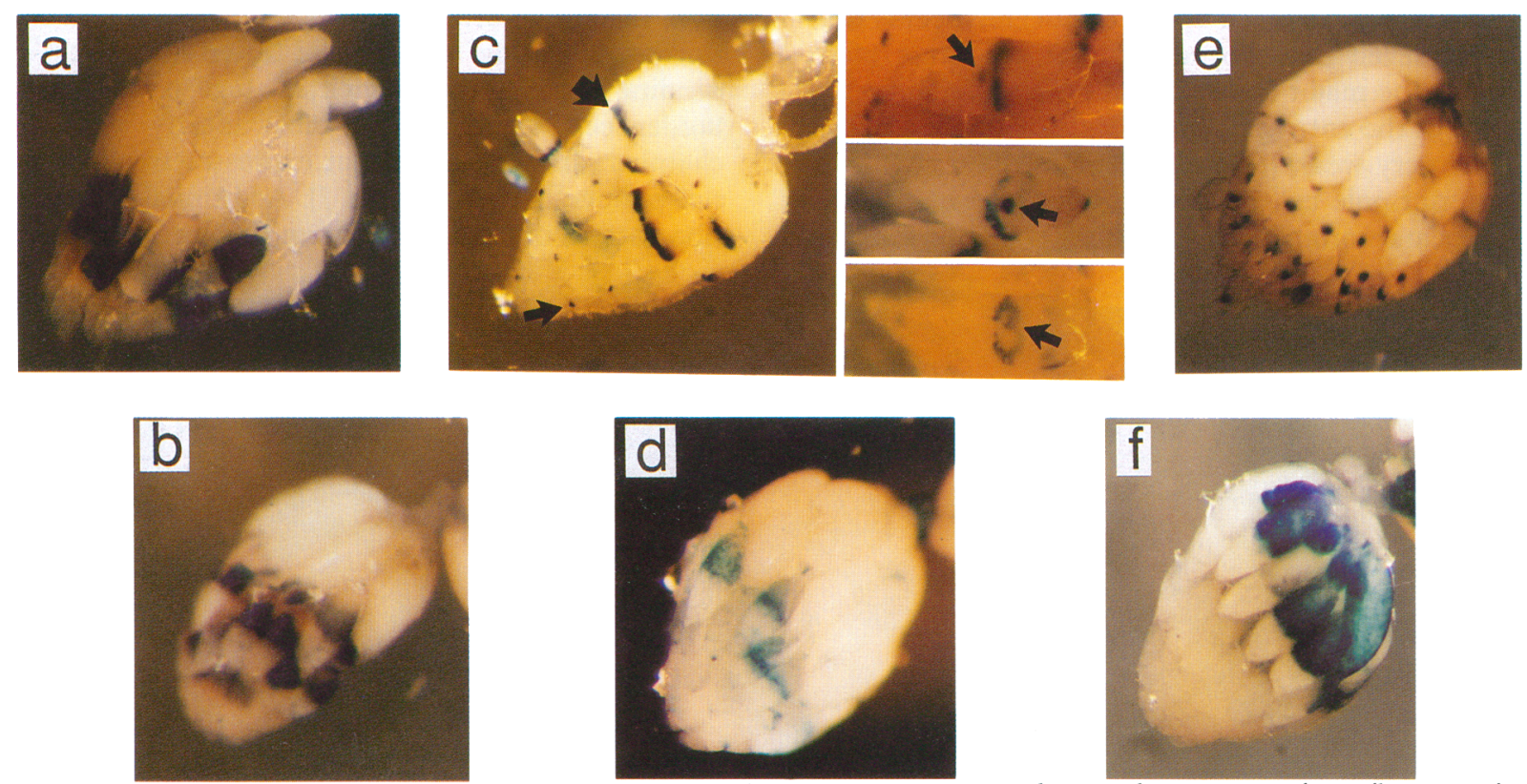

Figure 6. $\beta$-Galactosidase staining patterns directed by oel and oel components. X-gal stained ovaries are from flies transformed with the following structures of Fig. 3: structure $\mathrm{c}(a)$; structure $\mathrm{d}(b)$; structure e $(c)$; structure $\mathrm{f}(d)$; structure e $(e)$; structure $\mathrm{h}(f)$. Border cells (thin arrows) and anterior pole cells (thick arrows) are indicated. 

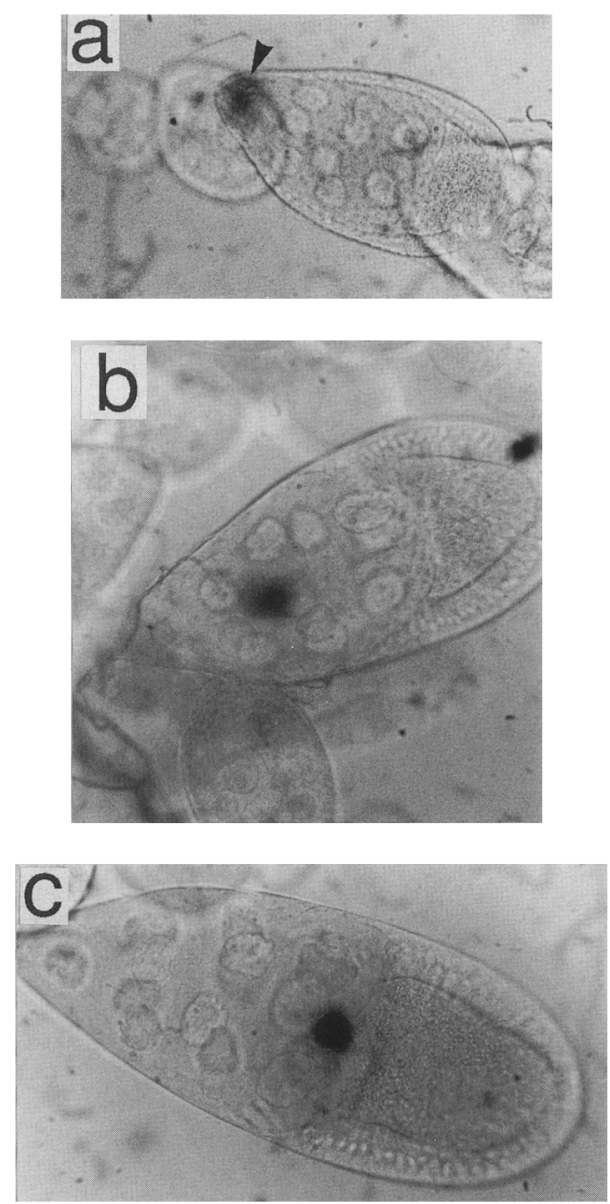

Figure 7. Border cell staining in egg chambers. $\beta$-Galactosidase-stained egg chambers from flies transformed with structure e of Fig. 3 . These cells migrate from a position at the anterior $(a$, arrowhead), between the nurse cells $(b)$, to the surface of the oocyte $(c)$.

some of the $y p-h s p-l a c Z$ fusion constructs. The yolk protein intergenic region extending to -343 does not direct the $h s p$ promoter to produce detectable levels of RNA in ovaries (Fig. 8A,B, structure d). This result is in accord with the absence of ovarian staining in flies transformed with this structure (Garabedian et al. 1986). The absence of staining and transcripts is not likely to be due to a nonfunctional promoter, as this structure produces RNA and staining in fat bodies (Garabedian et al. 1986). It is more likely to be due to deletion of both oel and oe 2 enhancers. Adding the remainder of the intergenic region produces detectable levels of ovarian transcripts in both of the lines examined (Fig. 8A,B, structure e, lanes 5 and 6). This result is in accord with the staining pattern from this structure (Logan et al. 1989) and with the presence of oel (Figs. 3d and 6b). When the yolk protein DNA is extended farther to include the oe2 region, ovarian transcripts are still produced, apparently at the same level (Fig. 8A,B, structure $\mathrm{f}$, lanes 7 and 8). This result also is in accord with staining patterns (Fig. 6a). We conclude that there is a qualitative correlation between transcript levels and staining produced by fusions between the yolk protein regulatory regions and the $h s p-l a c Z$ reporter.

We also assayed ovarian transcripts from analogous yp1M13 structures (Fig. 8A,B, structures $\mathrm{a}$, b, and c). As expected, the structure without oel and oe 2 produced no detectable ovarian transcripts, whereas that with oel and oe 2 gave high levels of ovarian transcripts (structures a and c). The structure with yp2 DNA removed by truncation at -2 produced no detectable RNA. This result differs from the staining patterns, suggesting that the $h s p$ reporter structure and the $y p 1$ promoter respond differently to yolk protein ovarian regulation. Previous observations concerning the fat body enhancer of yolk protein genes offer an explanation for this differing response (Logan et al. 1989). The fat body enhancer influence on the yp1 promoter was also blocked when $y p 2$ DNA was removed by truncating at the same -2 site. This result was explained by speculation that there is normally an equilibrium between the fat body enhancer interactions with the yp1 promoter and the yp2 promoter, but truncation at -2 shifted the equilibrium toward nonproductive interactions with the damaged $y p 2$ promoter (Logan et al. 1989). We speculate that truncation at -2 also blocks oel influence on the $y p 1$ promoter, but permits influence on the more sensitive hsp 70 promoter.

Although the differential effect of truncation at -2 is subject for speculation, it does not alter the basic conclusions about the $h s p-l a c Z$ reporter structure. The staining levels correlate well with transcript levels from the same yolk protein-reporter fusions. Moreover, the yolk protein enhancers and enhancer components direct the reporter to produce staining only in the expected cell types.

\section{Discussion}

Cell-type specificity of transcription from yp1 and yp2 promoters: Ovarian expression appears limited to one pathway of cell differentiation

Analysis of expression from the pCR2 fusion construct demonstrates that the $y p 1$ and $y p 2$ promoter regions and intergenic DNA are sufficient to direct both promoters to express in the same developmental pattern. This expression pattern is highly specific and apparently normal because it is limited to ovaries and fat body cells of the adult female (Figs. 4 and 5). In addition, expression is limited to particular follicle cell types at the expected stages of egg chamber development. This pattern is in accord with previous lower resolution studies of transcripts from the endogenous chromosomal pair of yolk protein genes (Barnett et al. 1981; Brennan et al. 1982; Garabedian et al. 1985, 1986). The only apparent difference from endogenous gene studies is that reporter protein activity persists in two follicle cell populations (anterior and posterior pole cells) during late stages of egg chamber development (Brennan et al. 1982). The late stage activity that we observe may be due either to coincidentally longer half-lives of both $A d h$ and lacZ fusion 

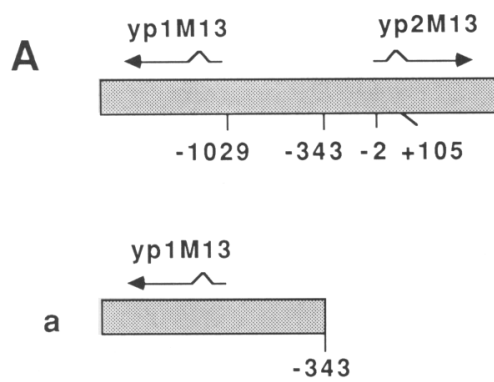

b

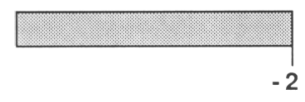

c

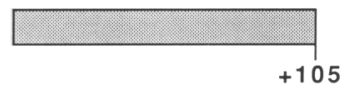

d

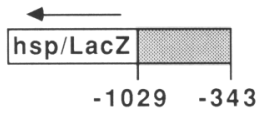

e

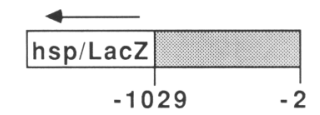

f

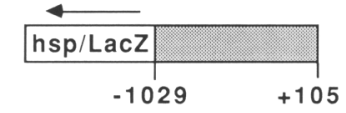

B

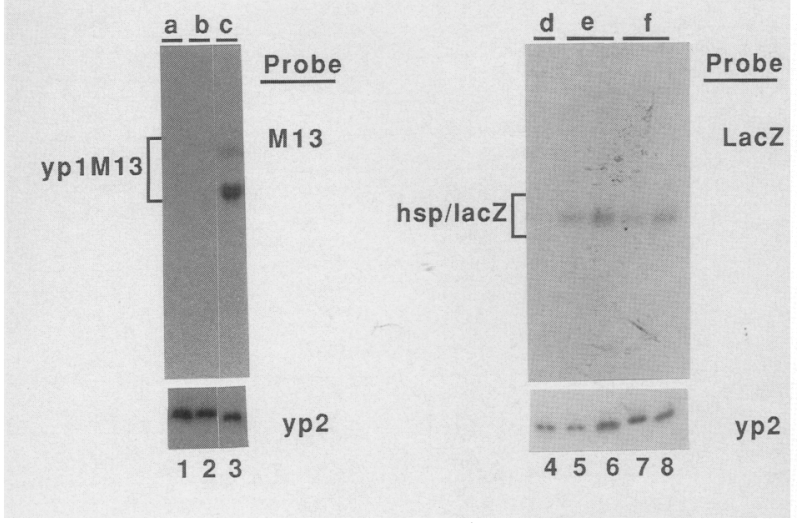

Figure 8. Ovarian transcription from fusion genes. Labeling conventions are as in Fig. 3 . $|A|$ The structure of $y p(1+2) \mathrm{M} 13 / \mathrm{shaded}$ box, top $)$. The yolk protein nucleotide positions indicate the end points of yolk protein DNA upstream of yp1M13 (a-c) or upstream of $h s p-l a c Z(d-f)$. $(B)$ Autoradiograph of Northern blots of total ovarian RNA from flies transformed with structures shown in $A$. $(a-f)$ The constructs. RNA is from dissected ovaries ( $5 \mu \mathrm{g}$ RNA/lane, $a-c ; 10 \mu \mathrm{g}$ RNA/lane, $d-f)$. Gel blots were hybridized to radiolabeled M13 (lanes 1-3) or radiolabeled lacZ DNA (lanes 4-8). Below is an autoradiograph of the same blots rehybridized to a yp2 probe after removal of M13 label. This control indicates that there are similar amounts of RNA in each lane.

gene products in both cell populations or to the high sensitivity and specificity of the enzymatic assays.

Examination of the ovarian cell-type specificity of pCR2 expression indicates that the yp1+2 segment directs expression in a particular pathway of follicle cell differentiation. Expression is only observed in columnar follicle cells and their descendants (anterior pole cells, columnar main body cells, and occasionally in posterior pole cells and main body cells; Fig. 1). Other cell types derived from follicle cell precursors do not express yolk protein genes, namely, the border cells and the cells covering the nurse cells. Limitation of expression to this pathway does not appear to be due to low stability of the fusion transcripts or proteins in nonexpressing cell types because a similar $\beta$-galactosidase fusion protein is expressed in border cells (Figs. 6 and 7) and in almost all tissues of the fly (Lis et al. 1983; Garabedian et al. 1986). Thus, ovarian transcription of yolk protein genes appears restricted to one pathway of cell differentiation.

\section{Component structure of oe1}

As summarized in Figure 3 and illustrated in Figure 6, deletions within oel alter the expression pattern. This indicates that oel is comprised of several components with differing cell-type specificities. The simplest model to explain the results is that a 149-bp region $(-134$ to -282 ) directs border cell and anterior pole cell specificity, whereas an adjacent 91 -bp region $(-43$ to -133$)$ acts negatively to suppress expression in the border cells and positively to direct expression in columnar main body cells.

The component structure of the oel enhancer found in this analysis of expression in the whole organism is similar to enhancer structures revealed by previous analyses that used cultured cells (for review, see Atchison 1988). Studies with cultured cells also revealed, once again like oel, that enhancer components can have positive or negative effects on the inducibility or the celltype specificity of the enhancer influences (e.g., Wasylyk and Wasylyk 1986; Hammer et al. 1987; Imler et al. 1987; Kuhlemeier et al. 1987; Goodbourn and Maniatis 1988).

Cell transformation and biochemical studies of other enhancers suggest the mechanism by which oel components direct different specificities during follicle cell differentiation in the organism. The biochemical studies indicate that different combinations of components allow different combinations of regulatory proteins to bind cooperatively, thereby regulating the level of transcription under different developmental, environmental, and physiological conditions (Yamamoto 1985; Keleher et al. 1988; Keller and Maniatis 1988).

Recent enhancer trap surveys indicate that oel components may bind regulatory proteins that determine basic follicle cell subtypes (Fasano and Kerridge 1988; Grossniklaus et al. 1989|. These surveys have detected a number of enhancers that influence expression in follicle cells. Although these enhancers have not been subdivided or extensively characterized, the patterns of expression found suggest that oel components direct several of the most common follicle cell expression patterns. These are the border cell, the anterior pole cell, the main body, and the posterior pole cell patterns.

\section{A region of oe1 is homologous to oe2, yp3, and an ecdysone response element}

Results described in this paper demonstrate that the 102-bp ovarian regulatory region located within the first exon of yp2 is a follicle-cell-specific enhancer. Although this region, oe 2 , directs transcription in follicle cells, the stage specificity of expression is altered relative to wildtype expression (Fig. 6f). Thus, in its normal context, oe2 
may play no role in determining stage specificity. Alternatively, the entire oe 2 enhancer may extend beyond the fragment tested and include adjacent sequences that regulate stage specificity. A third possibility is that the stage-specific influence of the oe2 fragment may be affected by spacing or orientation relative to the $h s p$ promoter. In any case, we conclude that the $y p 1+2$ region has two enhancers (oel and oe2) specifying follicle cell expression.

Because both oel and oe2 direct similar cell-type specificities, we compared them for sequence homologies. Many were found. Noteworthy is a region of oel that is not only homologous to oe2 but also to the yp3 gene and an ecdysone response element (Fig. 9). Within this oel region is a 9-nucleotide segment homologous to both oe2 (7 of 9 nucleotides) and yp3 ( 9 of 9$)$. This segment is adjacent to a 12-nucleotide segment homologous to a different region of $y p 3$ ( 11 of 12 nucleotides; Fig. 9). The homology to yp3 is of interest because yp3, the third Drosophila yolk protein gene, is expressed in the same developmental pattern as yp1 and yp2 (Bownes and Hames 1978; Brennan et al. 1982; Garabedian et al. 1987).

The ecdysone response element of the Drosophila hsp27 gene (Riddihough and Pelham 1987) is homologous to both oel and oe2 DNA in this region (Fig. 9). For example, from oel nucleotides -124 to -112 , there is a homology of 12 of 13 nucleotides to the response element. The ecdysone element homology may be related to the ecdysone dependence of yolk gene expression (Postlethwait and Handler 1979; Jowett and Postlethwait 1980; Bownes et al. 1983). Although homology to this hormone response element is suggestive, the yolk protein gene response to the hormone may be indirect.

\section{Genes influencing follicle cell differentiation}

Ovarian follicle cells synthesize and secrete both egg shell proteins and yolk proteins (Mahowald and Kambysellis 1980; and Margaritis et al. 1980). For this reason, it seems likely that genes controlling the differentiation of the egg shell pattern may also control the differentiated pattern of yolk protein gene expression that we have observed in this study. Two genes, torpedo and gurken, have been shown to influence the dorsoventral pattern of the egg shell differentiation (Schupbach 1987; Price et al. 1989). Their mutant phenotypes raise the possibility that the organization of egg shell structure is determined by a set of pattern formation genes analogous to the extensively studied homeotic and segmentation genes that determine expression patterns during early Drosophila development (Ingham 1988). Therefore, oel, which can direct the pattern of yolk protein gene expression in follicle cells, may be influenced by torpedo, gurken, and other egg pattern genes.

\section{Materials and methods}

\section{Construction of P-element plasmids}

The $y p(1+2)$ M13 deletion was made by deleting the DNA between -164 and +4 using standard techniques (Schleif and Wensink 1981; Maniatis et al. 1982) and the restriction sites found in the sequence (Hung and Wensink 1981, 1983). The initial yp $(1+2) \mathrm{Ml3}$ structure was assembled from pYP1-M13 676 and pYP2-M13 ${ }_{676}$ by fusion at the intergenic HindIII site (Garabedian et al. 1985). The final structure was cloned into the CP20.1 P-element transformation vector (Simon et al. 1985).

The yp-hsp-lacZ fusion genes were made by placing yolk protein DNA fragments into SalI or $\mathrm{XbaI}$ sites of a polylinker located 195 bp upstream of the $h s p 70$ promoter in a $h s p-l a c Z$ fusion gene. When these constructs are inserted into the Drosophila germ line, yolk protein DNA is flanked upstream by $\sim 7.2$ $\mathrm{kb}$ of rosy (ry) gene DNA and downstream by $\sim 7.3 \mathrm{~kb}$ of $h s p-$ lacZYA DNA. The transformation vector was made by modification of the ends of a XhoI-XbaI fragment from pSP1.1 (Lis et al. 1983) containing the $h s p-l a c Z$ gene and then insertion of it into the pUCl3 polylinker of the transformation vector $\mathrm{CP} 20.1$ (Simon et al. 1985). The resulting vector, pSXhLac-7 (constructed by Claude Maina), has the fusion site $5^{\prime}-\mathrm{G} / \mathrm{GTCGAC/}$ TCTAGA/GTCGAGAAATTT-3' (the SalI and XbaI sites are bounded by slash marks and the $h s p 70$ DNA, which begins at -195 , is underlined). The Sall and XbaI sites are unique in pSXhLac- 7 . The deletion to -134 bp upstream of yp 2 was made by $B A L-31$ exonuclease digestion followed by addition of a SalI linker to the resected end. This DNA was sequenced to determine the fusion site.

pCR2 has a $X b a I-H i n d I I I$ fragment containing the alcohol dehydrogenase structural gene from $D$. melanogaster (Bonner et al. 1984) fused at its HindIII site in the nontranslated leader region to the AvaII site in yp1 (+37 of yp1) through a linker (5'-AAGAGGGCTGCAAAGCTCTCTAGAGGTCCTGCGG$3^{\prime}$; the fusion site was verified by sequencing; underlining indicates the $A d h$ sequence beginning at +21 relative to the larval cap site and the modified HindIII and AvaII sites in $5^{\prime}$ to $3^{\prime}$ order). The yolk protein component of pCR2 extends to the NcoI site in yp2 $(+105$ of $y p 2\}$, which is fused to the SmaI site of a modified E. coli lacZ gene [pMLB1034( $\triangle A v a I)$; Shapira et al. 1983 ) by a linker $\left(5^{\prime}\right.$-GCCATGCGGTCGACCGGGGATCCC$3^{\prime}$; underlining indicates the $\mathrm{NcoI}$ and $S \mathrm{maI}$ sites remaining in pCR2). The 3' end of the $l a c Z$ gene region was terminated at the Ball site by insertion of a 620-bp HpaI-HindIII fragment from the D. melanogaster $\alpha 1$-tubulin gene (Theurkauf et al. 1986) that contains the $\alpha 1$ polyadenylation site in the appropriate ori-

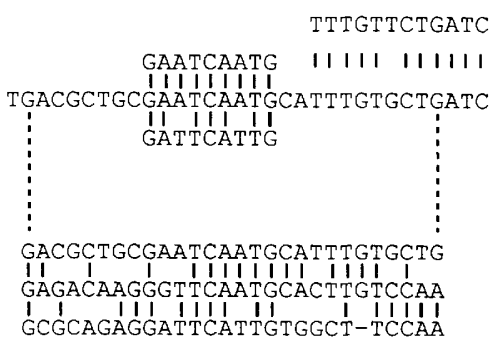

yp3 $(-1566$ to -1577$)$

yp3 $(-632$ to -640$)$

oe1 $(-134$ to -105$)$

oe2 $(+58$ to +50$)$ oe $1(-133$ to -108$)$

ecdysoné response element

oe2 $(+66$ to +40$)$
Figure 9. Sequence homologies. The nucleotide sequence boundaries are shown in parentheses. The vertical lines indicate nucleotide identities. 
entation. This structure was inserted into the P-element transformation vector CP20.1 forming the complete pCR2.

\section{Germ line transformation}

Transformation procedures were carried out according to Spradling and Rubin (1982). Embryos from a $r y^{-}$strain of Drosophila (ry $\left.\Delta^{506}\right)$ were injected with yp $1+2$ constructs at 350 $\mu \mathrm{g} / \mathrm{ml}$ and a defective $P$ element, $P \pi 25.7$ w.c., at $150 \mu \mathrm{g} / \mathrm{ml}$ (Karess and Rubin 1984). The yp-lacZ transformants were inbred, whereas the $y p-A d h$ transformants were crossed into an $A d h^{\text {fno }}$ background according to the general procedure of Fischer and Maniatis (1988), as follows. The transformants, distinguishable by their wild-type $\left(r y^{+}\right)$eye color, were individually crossed with flies from an $A d h^{f n 6} \mathrm{Cn}_{i} \mathrm{ry}^{506}$ (FCR) strain. The $\mathrm{ry}^{+} \mathrm{G}_{1}$ male progeny from this cross were then mated with virgin females from the $A d h^{f n o} \mathrm{cn} ; M K R S / T M 2$; ry (FCB) strain. The progeny from this mating, which possessed the $\mathrm{P}$ element and were homozygous for the $A d h^{\text {fno }} \mathrm{cn}$ chromosome, could be distinguished by their bright $\mathrm{ry}^{+} \mathrm{Cn}^{-}$eye color. This phenotype was most easily observed shortly after eclosion when eyes of the homozygotes appear almost fluorescent. The eye color of the $G_{2}$ generation also indicates the chromosome into which the P element has inserted (Fischer and Maniatis 1988).

\section{Analysis of transformants}

Because ovary development is strongly affected by age and nutrition, all flies for RNA analysis or histochemical staining were collected after eclosion and aged 3-5 days on food supplemented with live yeast paste. The staining assay allows us to examine many egg chambers easily and leads us to believe that yolk protein expression varies between ovaries of flies that have been fed differently or have other differences in their growth conditions.

The techniques used for isolating and examining nucleic acids have been described by Kalfayan and Wensink (1982) and Garabedian et al. (1985). All Northern blots were hybridized to 32P-labeled DNA probes.

Southern blot analysis was used to determine that each line described was independently transformed and has a single, unrearranged copy of the introduced gene structure.

\section{$\beta$-Galactosidase histochemical staining}

The X-gal (5-bromo-4-chloro-3-indolyl- $\beta$-galactopyranoside) assay for $\beta$-galactosidase activity has been described ( $\mathrm{Lis}$ et al. 1983). Flies were dissected in X-gal staining buffer and allowed to stain overnight. If it was desirable to preserve tissue morphology (e.g., to examine individual egg chambers), tissue was fixed in $0.6 \mathrm{ml} 37 \%$ formaldehyde $/ 5 \mathrm{ml}$ Ringer's solution for $\sim 5$ min. Tissue was then washed in Ringer's for 5-10 min and stained. Ovarian tissue appears to be sensitive to $\mathrm{pH}$ and is best preserved in stain buffer at $\mathrm{pH} 6.8$ to $\mathrm{pH} 7$.

\section{$A D H$ histochemical staining and spectrophotometric assay}

Flies were prepared for ADH staining by dissection in TB1 [15 $\mathrm{mM} \mathrm{KPO}_{4}$ (pH 7), $80 \mathrm{mM} \mathrm{KCl}, 16 \mathrm{mM} \mathrm{NaCl}, 5 \mathrm{~mm} \mathrm{MgCl}, 1 \%$ polyethylene glycol (Bonner et al. 1984)] and subsequent fixation in $1 \%$ glutaraldehyde (Polysciences, E.M. grade) in Ringer's solution. Tissue was immersed $(3 \times)$ for 10 -min in Ringer's solution. The above procedures were done on ice with prechilled solutions. ADH staining then was carried out at room temperature. To avoid nonspecific staining, the procedure was done in the dark with stain buffer that was kept on ice before the assay.
The ADH activity stain buffer was made according to O'Donnell et al. (1975), as follows: $1.4 \mathrm{ml}$ potassium phosphate $(\mathrm{pH}$ 7.5), $250 \mu \mathrm{l} \mathrm{NBT}$ (nitroblue tetrazolium, $5 \mathrm{mg} / \mathrm{ml}$ stock), $50 \mu \mathrm{l}$ NAD (Sigma grade V, $50 \mathrm{mg} / \mathrm{ml}$ stock), $25 \mu$ l PMS (phenazine methosulfate, $2 \mathrm{mg} / \mathrm{ml}$ stock), and $50 \mu \mathrm{l}$ 2-butanol. Tissue was then destained $30 \mathrm{~min}$ to overnight in $70 \%$ ethanol, $5 \%$ acetic acid. In this procedure, specific ovarian staining occurred in 5-10 min.

The spectrophotometric assay of $\mathrm{ADH}$ activity was modified from Bonner et al. (1984). Flies, 3-5 days old, 1 female or 5 males, were homogenized in $350 \mu \mathrm{l} \mathrm{TB} 1$ to which $3.5 \mu \mathrm{l}$ PMSF (100 mM phenylmethylsulfonyl fluoride in dimethylsulfoxide) had been added. The homogenates were then centrifuged 1-2 min in a microfuge and resulting supernatants transferred to a fresh microfuge tube. The reaction was started by adding $13 \mu \mathrm{l}$ NAD (50 mg/ml stock) and $11 \mu \mathrm{l} 2$-butanol and rapidly transferring to a microcuvette. Activity was measured at $340 \mathrm{~nm}$ as the difference between initial absorbance and the absorbance 2 min later.

\section{Acknowledgments}

We thank Kim O'Donnell, Marie Lossky, Karen Coschigano, Susan Hardin, Doug Jacoby, and Bob Kolouch for helpful criticism of this manuscript. We also thank José Bonner and Michael Casadaban for the gifts of modified $A d h$ and lacZ genes. The assistance of Marcia Lipson and Elissa Simon in constructing pCR2 and Paul Mitsis in constructing the computer drawings of egg chambers is gratefully acknowledged. This research was supported by the National Institutes of Health (R01-GM21626).

\section{References}

Atchison, M.L. 1988. Enhancers: Mechanisms of action and cell specificity. Annu. Rev. Cell Biol. 4: 127-153.

Barnett, T. and P.C. Wensink. 1981. Transcription and translation of yolk protein mRNA in the fat bodies of Drosophila. In Developmental biology using purified genes. UCLA-ICN Symposium, vol. 23 (ed. D.D.Brown and C.F. Fox), pp. 97-106. University of California Press, Berkeley.

Barnett, T., C. Pachl, P.J. Gergen, and P.C. Wensink. 1980. The isolation and characterization of Drosophila yolk protein genes. Cell 21: 729-738.

Bonner, J.J., C. Parks, J. Parker-Thornburg, M.A. Mortin, and H.R.B. Pelham. 1984. The use of promoter fusions in Drosophila genetics: Isolation of mutations affecting the heat shock response. Cell 37: 979-991.

Bownes, M. and B.D. Hames. 1978. Analysis of yolk proteins in Drosophila melanogaster. FEBS Lett. 96: 327-330.

Bownes, M., M. Blair, R. Kozma, and M. Dempster. 1983. 20Hydroxyecdysone stimulates tissue-specific yolk-protein gene expression in Drosophila. J. Embryol. Exp. Morphol. 78: $249-268$.

Brennan, M.D., A.J. Weiner, T.J. Goralski, and A.P. Mahowald. 1982. The follicle cells are a major site of vitellogenin synthesis in Drosophila melanogaster. Dev. Biol. 89: 225-236.

Fasano, L. and S. Kerridge. 1988. Monitoring positional information during oogenesis in adult Drosophila. Development 104: $245-253$.

Fischer, J.A. and T. Maniatis. 1988. Drosophila Adh: A promoter element expands the tissue specificity of an enhancer. Cell 53: 451-461

Garabedian, M.J., M.C. Hung, and P.C. Wensink. 1985. Independent control elements that determine yolk protein gene 
expression in alternative Drosophila tissues. Proc. Natl. Acad. Sci. 82: 1396-1400.

Garabedian, M.J., B.M. Shepherd, and P.C. Wensink. 1986. A tissue-specific transcription enhancer from the Drosophila yolk protein 1 gene. Cell 45: 859-867.

Garabedian, M.J., A.D. Shirras, M. Bownes, and P.C. Wensink. 1987. The nucleotide sequence of the gene coding for Drosophila melanogaster yolk protein 3. Gene 55: 1-8.

Goodboum, S. and T. Maniatis. 1988. Overlapping positive and negative regulatory domains of the human $\beta$-interferon gene. Proc. Natl. Acad. Sci. 85: 1447-1451.

Grossniklaus, U., H.J. Bellen, C. Wilson, and W.J. Gehring. 1989. P-element-mediated enhancer detection applied to the study of oogenesis in Drosophila. Development 107: 189200.

Hammer, R.E., R. Krumlauf, S.A. Camper, R.L. Brinster, and S.M. Tilghman. 1987. Diversity of alpha-fetoprotein gene expression in mice is generated by a combination of separate enhancer elements. Science 235: 53-58.

Hung, M.-C. and P.C. Wensink. 1981. The sequence of Drosophila melanogaster gene for yolk protein 1. Nucleic Acids Res. 9: 6407-6419.

-1983. Sequence and structure conservation in yolk proteins and their genes. J. Mol. Biol. 164: 481-492.

Imler, J.-L., C. Lemaire, C. Wasylyk, and B. Wasylyk. 1987. Negative regulation contributes to tissue specificity of the immunoglobulin heavy chain enhancer. Mol. Cell. Biol. 7: $2558-2567$.

Ingham, P.W. 1988. The molecular genetics of embryonic pattern formation in Drosophila. Nature 335: 25-34.

Jowett, T. and J.H. Postlethwait. 1980. The regulation of yolk polypeptide synthesis in Drosophila ovaries and fat body by 20-hydroxyecdysone and a juvenile hormone analogue. Dev. Biol. 80: 225-234.

Kalfayan, L. and P.C. Wensink. 1982. Developmental regulation of Drosophila $\alpha$-tubulin genes. Cell 29: 91-98.

Karess, R.E. and G.M. Rubin. 1984. Analysis of P transposable element functions in Drosophila. Cell 38: 135-146.

Keleher, C.A., C. Goutte, and A.D. Johnson. 1988. The yeast cell-type-specific repressor $\alpha 2$ acts cooperatively with a non-cell-type-specific protein. Cell 53: 927-936.

Keller, A.D. and T. Maniatis. 1988. Identification of an inducible factor that binds to a positive regulatory element of the human $\beta$-interferon gene. Proc. Natl. Acad. Sci. 85: 33093313.

King, R.C. 1970. Ovarian development in Drosophila melanogaster, Academic Press, New York.

Kuhlemeier, C., R. Fluhr, P.J. Green, and N.-H. Chua. 1987. Sequences in the pea rbcS-3A gene have homology to constitutive mammalian enhancers but function as negative regulatory elements. Genes Dev. 1: 247-255.

Lis, J.T., J.A. Simon, and C.A. Sutton. 1983. New heat shock puffs and $\beta$-galactosidase activity resulting from transformation of Drosophila with an hsp70-lacZ hybrid gene. Cell 35: 403-410.

Logan, S.K., M.J. Garabedian, and P.C. Wensink. 1989. DNA regions which regulate the ovarian transcriptional specificity of Drosophila yolk protein genes. Genes Dev. 3: $1453-1461$.

Mahowald, A.P. and M.P. Kambysellis. 1980. Oogenesis. In The genetics and biology of Drosophila, vol. 2d, led. M. Ash-

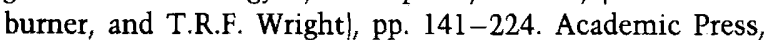
New York.

Maniatis, T., E.F. Fritsch, and J. Sambrook. 1982. Molecular cloning: A laboratory manual. Cold Spring Harbor Laboratory Press, Cold Spring Harbor, New York.
Margaritis, L.H., F.C. Kafatos, and W.H. Petri. 1980. The eggshell of Drosophila melanogaster, I. Fine structure of the layers and regions of the wild-type eggshell. I. Cell Sci. 43: $1-35$.

O’Donnell, J., L. Gerace, F. Leister, and W. Sofer. 1975. Chemical selection of mutants that affect alcohol dehydrogenase in Drosophila. II. Use of 1-pentyne-3-ol. Genetics 79: 7383.

Postlethwait, J.H. and A.M. Handler. 1979. The roles of juvenile hormone and 20-hydroxyecdysone during vitellogenesis in isolated abdomens of Drosophila melanogaster. $I$. Insect Physiol. 25: 455-460.

Price, I.V., R.J. Clifford, and T. Schupbach. 1989. The maternal ventralizing locus torpedo is allelic to faint little ball, an embryonic lethal, and encodes the Drosophila EGF receptor homolog. Cell 56: 1085-1092.

Riddihough, G. and H.R.B. Pelham. 1987. An ecdysone response element in the Drosophila hsp27 promoter. EMBO I. 6: $3729-3734$

Schleif, R.F. and P.C. Wensink. 1981. Practical methods in molecular biology. Springer-Verlag, New York.

Schupbach, T. 1987. Germ-line and soma cooperate during oogenesis to establish the dorso-ventral pattern of egg shell and embryo in Drosophila melanogaster. Cell 49: 699-707.

Shapira, S.K., J. Chou, F.V. Richaud, and M.J. Casadaban. 1983. New versatile plasmid vectors for expression of hybrid proteins coded by a cloned gene fused to $l a c Z$ gene sequences encoding an enzymatically active carboxy-terminal portion of $\beta$-galactosidase. Gene 25: 71-82.

Shepherd, B.S., M.J. Garabedian, M.-C. Hung, and P.C. Wensink. 1985. Developmental control of Drosophila yolk protein 1 gene by cis-acting DNA elements. Cold Spring Harbor Symp. Quant. Biol. 50: 521-526.

Simon, J.A., C.A. Sutton, R.B. Lobell, R.L. Glaser, and J.T. Lis. 1985. Determinants of heat shock-induced chromosome puffing. Cell 40: 805-817.

Spradling, A.C. and G.M. Rubin. 1982. Transposition of cloned $\mathrm{P}$ elements into Drosophila germ line chromosomes. Science 218: $341-347$.

Theurkauf, W.E., H. Baum, J. Bo, and P.C. Wensink. 1986. Tissue-specific and constitutive $\alpha$-tubulin genes of Drosophila melanogaster code for structurally distinct proteins. Proc. Natl. Acad. Sci. 83: 8477-8481.

Wasylyk, C. and B. Wasylyk. 1986. The immunoglobulin heavy-chain $\beta$-lymphocyte enhancer efficiently stimulates transcription in non-lymphoid cells. EMBO /. 5: 553-560.

Yamamoto, K.R. 1985. Steroid receptor regulated transcription of specific genes and gene networks. Annu. Rev. Genet. 19: $209-252$. 


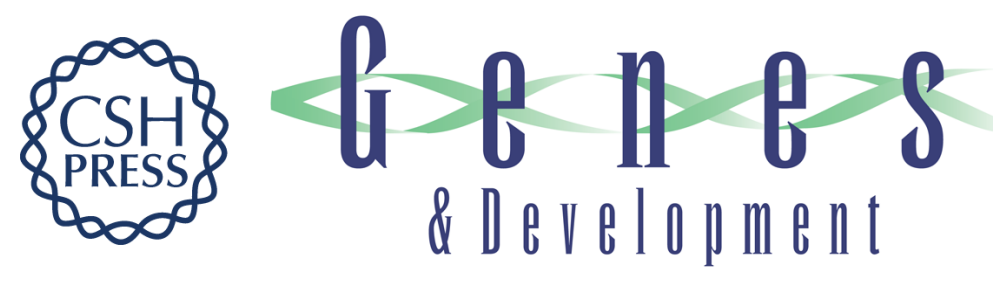

\section{Ovarian follicle cell enhancers from the Drosophila yolk protein genes: different segments of one enhancer have different cell-type specificities that interact to give normal expression.}

S K Logan and P C Wensink

Genes Dev. 1990, 4:

Access the most recent version at doi:10.1101/gad.4.4.613

References This article cites 39 articles, 14 of which can be accessed free at: http://genesdev.cshlp.org/content/4/4/613.full.html\#ref-list-1

License

Email Alerting Service

Receive free email alerts when new articles cite this article - sign up in the box at the top right corner of the article or click here.

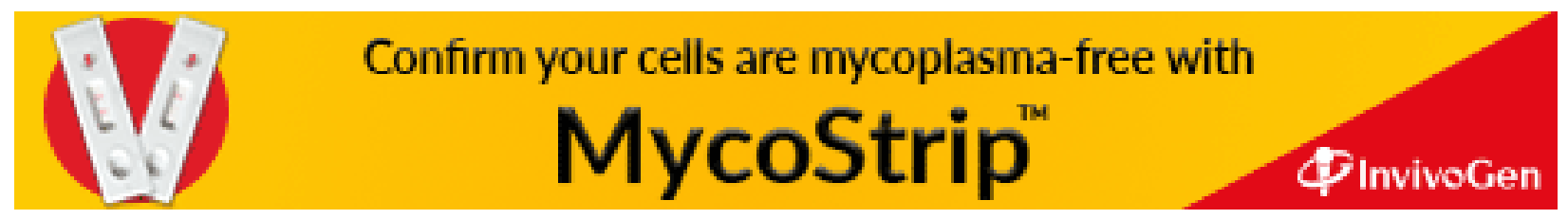

